\title{
Assessment of autonomic dysfunction following spinal cord injury: Rationale for additions to International Standards for Neurological Assessment
}

\author{
Andrei V. Krassioukov, MD, PhD; ${ }^{1 *}$ Ann-Katrin Karlsson, MD, PhD; ${ }^{2}$ Jill M. Wecht, PhD; ${ }^{3}$ Lisa-Ann \\ Wuermser, MD; ${ }^{4}$ Christopher J. Mathias, DPhil, DSc, FRCP, FMedSci; ${ }^{5}$ Ralph J. Marino, MD, MSCE ${ }^{6}$ \\ ${ }^{1}$ Department of Physical Medicine and Rehabilitation, International Collaboration on Repair Discoveries, University \\ of British Columbia, Vancouver, BC, Canada; ${ }^{2}$ Institute of Neuroscience and Physiology, Sahlgrenska Academy, \\ Gothenburg, Sweden; ${ }^{3}$ Department of Veterans Affairs (VA) Rehabilitation Research and Development Center \\ of Excellence Spinal Cord Injury and Medical Services, VA Medical Center, Bronx, NY; ${ }^{4}$ Department of Physical \\ Medicine and Rehabilitation, Rehabilitation Institute of Chicago, Chicago, IL; ${ }^{5}$ Neurovascular Medicine Unit, Faculty \\ of Medicine, Imperial College London, London, UK; and Autonomic Unit, National Hospital for Neurology and \\ Neurosurgery, Institute of Neurology, Queen Square, University College London, London, UK; ${ }^{6}$ Department of \\ Rehabilitation Medicine, Thomas Jefferson University, Philadelphia, PA
}

\begin{abstract}
We present a preliminary report of the discussion of the joint committee of the American Spinal Injury Association (ASIA) and the International Spinal Cord Society concerning the development of assessment criteria for general autonomic function testing following spinal cord injury (SCI). Elements of this report were presented at the 2005 annual meeting of the ASIA. To improve the evaluation of neurological function in individuals with SCI and therefore better assess the effects of therapeutic interventions in the future, we are proposing a comprehensive set of definitions of general autonomic nervous system dysfunction following SCI that should be assessed by clinicians. Presently the committee recommends the recognition and assessment of the following conditions: neurogenic shock, cardiac dysrhythmias, orthostatic hypotension, autonomic dysreflexia, temperature dysregulation, and hyperhidrosis.
\end{abstract}

Key words: assessment standards, autonomic dysfunction, autonomic dysreflexia, bradycardia, cardiovascular control, orthostatic hypotension, rehabilitation, spinal cord injury, sweating, temperature.

\section{INTRODUCTION}

That autonomic dysfunctions, including abnormal cardiovascular control, are common consequences of spinal cord injury (SCI) in humans is well known. During the first weeks postinjury, alterations in autonomic function may be life-threatening. Severe bradycardia and even asystole are seen in patients with cervical injuries. The majority of these patients require admission to the intensive care unit because of hemodynamic instability, including severe

Abbreviations: $\mathrm{AD}=$ autonomic dysreflexia, $\mathrm{ASIA}=$ American Spinal Injury Association, ECG = electrocardiogram, HF = high frequency, HR = heart rate, HRV = HR variability, HUT = headup tilt, ISCoS = International Spinal Cord Society, LF = low frequency, $\mathrm{SCI}=$ spinal cord injury, $\mathrm{T}=$ thoracic.

* Address all correspondence to Andrei V. Krassioukov, MD, PhD; Department of Physical Medicine and Rehabilitation, ICORD, University of British Columbia, 6270 University Blvd, Vancouver, BC, Canada, V6T 1Z4; 604-822-2673; fax: 604-822-2924. Email: krassioukov@icord.org

DOI: 10.1682/JRRD.2005.10.0159 
hypotension or bradycardia [1-2]. However, patients who do not need intensive care unit admission also need to be carefully monitored for autonomic instability during the initial postinjury period. Little is known about the connection between the severity and level of SCI and the severity of autonomic dysfunction. Furthermore, no data on humans are available regarding the effect of low blood pressure and heart rate (HR) abnormalities on the risk of neurological deterioration following SCI [2]. During the last decade, we have developed and significantly improved the assessment of individuals with SCI. However, the International Standards for Neurological Assessment, commonly referred to as the American Spinal Injury Association (ASIA) examination, only evaluate motor and sensory functions following SCI [3]. Although a battery of clinical tests to assess autonomic functions is available, the complexity and organization of the autonomic nervous system and its involvement in the control of almost every system in the body make selecting appropriate autonomic function tests for individuals with SCI difficult. Furthermore, experience with these tests in the clinical assessment of individuals with SCI is very limited, and uniform operational definitions of dysfunction are lacking.

To improve the evaluation of autonomic function in individuals with SCI and in the future assess the effects of therapeutic interventions, the ASIA and International Spinal Cord Society (ISCoS) established a committee to develop a set of definitions and classifications for disorders of autonomic function in SCI. In this article, the general autonomic dysfunction subcommittee proposes a comprehensive set of definitions of autonomic dysfunction following SCI that should be assessed by clinicians. Three additional subcommittees are working on definitions for bowel, bladder, and sexual functions, which will be addressed separately. Presently the committee recommends the recognition and assessment of the following conditions: neurogenic shock, cardiac dysrhythmias, orthostatic hypotension, autonomic dysreflexia (AD), temperature dysregulation, and hyperhidrosis (Figure). This article reviews the basis for these definitions.

\section{NEUROGENIC SHOCK}

Acute SCI in humans generally causes a drop in blood pressure; in cervical injuries, it can cause severe hypotension and bradycardia, which are common components of the phenomena known as neurogenic shock [4-6]. This phenomena is more profound and long lasting after SCI in humans than in experimental animals. Neurogenic shock is one manifestation of autonomic nervous system dysfunction observed following SCI [4,6-7]. Neurogenic shock is most likely an effect of the imbalance in autonomic control, with an intact parasympathetic influence via the vagal nerve and a loss of sympathetic tone because of disruption in supraspinal control. Clinical observations strongly suggest that prolonged and severe hypotension, requiring vasopressive therapy, is associated with the severity of the SCI and can last up to 5 weeks postinjury [4,8]. In one study, Glenn and Bergman reported that severe hypotension was present in all 31 tetraplegic subjects assessed with severe SCI, half of whom required vasopressive therapy to maintain adequate arterial blood pressure [9]. In addition to the pronounced hypotension described, many patients with acute SCI experience severe abnormalities in HR. Bradycardia was reported in 64 to 77 percent of patients with cervical SCI during the acute postinjury phase and was more severe and frequent within the first 5 weeks postinjury [10-12]. Interestingly, Furlan and colleagues reported that the hypotension and bradycardia observed initially after injury persisted in the individuals with more severe injury of the descending cardiovascular autonomic pathways [13]. Moreover, all individuals in this group required vasopressive therapy to maintain systolic arterial blood pressure above $90 \mathrm{mmHg}$. In contrast, individuals with less severe injury to the descending cardiovascular pathways tended to have higher blood pressure and HR, although minor and short-term hypotension and low HRs were occasionally observed.

In addition to neurogenic shock, the acute phase of SCI is also associated with "spinal shock" [14-16]. Some authors use these terms interchangeably; however, recognizing that these are two clinically important and distinct conditions is important. Neurogenic shock is characterized by changes in blood pressure and HR (autonomic) control following SCI $[4,6,8]$, whereas spinal shock is characterized by a marked reduction or complete loss of motor and reflex function below the injury level [16]. Clinically, spinal shock in humans can persist for days to weeks, with a mean duration of 4 to 6 weeks postinjury. Traditional views of the clinical course of the recovery of spinal shock were related to the emergence of certain groups of reflexes [16]. For example, some groups defined the end of spinal shock as the first few days postinjury when recovery of initial reflexes, such as the bulbocavernosus reflex, had occurred, other groups as 2 weeks postinjury when recovery of the 


\begin{tabular}{|c|c|c|c|}
\hline Condition & Definition & Yes & Degree \\
\hline Neurogenic Shock & $\begin{array}{l}\text { Commonly occurring condition following SCI associated with failure of } \\
\text { sympathetic nervous system that results in loss of vascular tone in part of } \\
\text { body deprived from autonomic control. } \\
\text { Operational definition: SBP }<90 \mathrm{mmHg} \text { in supine posture not result of low } \\
\text { intravascular volume (blood loss, dehydration). }\end{array}$ & & \\
\hline Bradycardia & $\begin{array}{l}\text { Deviations from normal HR. } \\
\text { Operational definition: Decrease in HR to }<60 \mathrm{bpm} \text {. } \\
\text { Severity: Mild, no symptoms, SPB }>90 \mathrm{mmHg} \text {; Moderate, requires } \\
\text { intervention to increase HR or maintain adequate BP; Severe, asystole. }\end{array}$ & & \\
\hline Orthostatic Hypotension & $\begin{array}{l}\text { Operational definition: Sustained decrease in } \mathrm{BP}>20 \mathrm{mmHg} \text { systolic or } \\
>10 \mathrm{mmHg} \text { diastolic occurring within } 3 \mathrm{~min} \text { when individual moves from } \\
\text { supine to upright posture. } \\
\text { Severity: Symptomatic (dizziness, headache, fatigue) or asymptomatic. }\end{array}$ & & \\
\hline Autonomic Dysreflexia & $\begin{array}{l}\text { Operational definition: Constellation of signs/symptoms in SCI above T5-T6 } \\
\text { in response to noxious or nonnoxious stimuli below injury level, including } \\
\text { increase in BP }>20 \text { mmHg above baseline, and may include one or more of } \\
\text { following: headache, flushing and sweating above lesion level, vasoconstriction } \\
\text { below lesion level, or dysrhythmias. May or may not be symptomatic and can } \\
\text { occur at any time following SCI. } \\
\text { Severity: Mild/partial, BP increase < } 40 \text { mmHg; Moderate, SBP rise } \\
>40 \text { mmHg, but SBP }<180 \text { mmHg; Severe, SBP }>180 \mathrm{mmHg} \text {. } \\
\text { Associated symptoms: piloerection, stuffy nose, other. }\end{array}$ & & \\
\hline Temperature Dysregulation & $\begin{array}{l}\text { Elevation or decrease of body temperature without signs of infection. May } \\
\text { result from exposure to environmental temperature change. }\end{array}$ & & \\
\hline $\begin{array}{l}\text { Sweating Disturbances } \\
\text { Hyperhidrosis } \\
\text { Hynohidrosis }\end{array}$ & $\begin{array}{l}\text { Nonphysiological sweating over portion of body in response to noxious/ } \\
\text { nonnoxious stimuli, positioning, etc. }\end{array}$ & & \\
\hline
\end{tabular}

Figure.

Comprehensive set of definitions of general autonomic nervous system dysfunction following spinal cord injury that should be assessed by clinicians. (Clinicians check Yes if present and indicate Degree.) BP = blood pressure, bpm = beats per minute, $\mathrm{HR}=$ heart rate, $\mathrm{SBP}=$ systolic blood pressure, $\mathrm{SCI}=$ spinal cord injury, $\mathrm{T}=$ thoracic.

deep tendon reflexes had occurred, while still other groups defined the end of spinal shock as $\sim 2$ months postinjury when recovery of the bladder reflex had occurred. For further details, we refer readers to the recent work of Ditunno and colleagues [16].

\section{CARDIAC DYSRHYTHMIAS}

Autonomic cardiovascular regulation is compromised following SCI, the degree to which relates to the level and completeness of the spinal cord lesion [13,1718]. In persons with injuries above the sixth thoracic $(\mathrm{T})$ vertebra, reductions in sympathetic cardiovascular control result in hypotension and bradycardia [19-20]. These abnormalities may directly reflect disruption of the sympathetic circuits within the upper thoracic segments (T1T5). However, cardiac efferent parasympathetic control, which arises from the brain stem, remains intact after SCI and may also contribute to the bradycardia observed in those with tetraplegia [21-22].

Bradycardia and cardiac arrest are known complications associated with the acute phase following SCI; these cardiac abnormalities are usually temporary [2223]. In the acute phase of SCI, stimuli to the trachea, such as suctioning, commonly induce bradycardia. Normally, 
this reflex is opposed by sympathetic activity, and during hypoxia, by increased pulmonary inflation from vagal reflex activity caused by increased breathing [22]. However, in individuals with cervical SCI, compensatory sympathetic activity is abolished by the cord lesion and increased pulmonary vagal reflex activity may be blocked by mechanical ventilation, which does not increase with hypoxia. Administration of atropine may be required in the acute phase of SCI. Following the acute phase, the risk of cardiac dysrhythmias is attenuated; however, evidence of late asystole requiring transvenous ventricular pacing has been found [24]. During the chronic phase of SCI, several investigators have reported a higher incidence of bradyarrhythmia in persons with tetraplegia but rarely in persons with paraplegia [24-25]. Researchers have also reported that persons with SCI have a higher incidence of nonspecific ST segment elevation and are at increased risk of developing electrocardiogram (ECG) abnormalities, such as premature atrial contractions, intraventricular conduction delays, and bundle-branch blocks compared with nondisabled individuals $[11,26]$. Others have reported similar ECG abnormality prevalence in the SCI population compared with the nondisabled population [26]. We would like to emphasize that dysrhythmias, particularly atrial fibrillation, may also occur during episodes of AD in individuals with high cord lesions and may require immediate pharmacological intervention to restore the normal rhythm [21,27].

Autonomic cardiovascular control influences HR through direct effects on the sinus node and modulation of circulating beta adrenergic agonist levels. The technique of HR variability (HRV) quantitatively assesses relative shifts in autonomic cardiac control. Using pharmacological blockade, researchers have determined the specific influences of vagal and sympathetic activity on HRV in the nondisabled population [28-30]. Atropine significantly reduced signal amplitudes within the low-frequency (LF) $(0.04-0.15 \mathrm{~Hz})$ and high-frequency (HF) $(0.15-0.40 \mathrm{~Hz})$ power spectrums during supine (LF: $-84 \%$; HF: $-92 \%$ ) and upright (LF: $-72 \%$; HF: $-95 \%)$ postures. On the other hand, propranolol has little effect on the power spectrum at supine rest and only reduced the LF amplitude with upright postures (-73\%) [29]. Thus, vagal influences appear to be present in both the LF and HF components of HRV during supine and upright postures, while sympathetic activity contributes to the LF component of HRV during upright postures only. The use of HRV tech- niques in persons with SCI has been reported [17-18,31]; however, the validity of this noninvasive approach in assessment of cardiovascular control in a population of individuals with severely affected autonomic efferent activity has not been thoroughly investigated. With this caveat, we present the following data on alterations in HRV in persons with SCI at rest and during provocations for stimulation of autonomic cardiovascular control. The higher and more complete the injury, the greater the reduction in both vagal and sympathetic activities, which indicates that the branches of the autonomic nervous system maintain a balance in the presence of SCI [17]. Clinicians commonly use the head-up tilt (HUT) to illuminate alterations in sympathetic cardiac modulation, which reflect the degree of autonomic dysfunction. Autonomic and cardiac responses to HUT are blunted in both persons with tetraplegia and paraplegia [32]. In fact, persons with paraplegia had comparable increases in HR during HUT as nondisabled persons, which were facilitated by the predominantly vagal withdrawal rather than the increased sympathetic activation that was demonstrated in nondisabled subjects. HRV techniques could be used to noninvasively assess cardiac autonomic control in persons with SCI, determine the degree of sympathetic disruption, and illuminate the potential risk of developing cardiac dysrhythmias. During the acute rehabilitation period, HRV can be a tool for monitoring improvements in autonomic outflow, and during the chronic phase of injury, it may document gains in function following physical and pharmacological interventions.

\section{ORTHOSTATIC HYPOTENSION}

Even as resting hypotension following SCI improves, loss of supraspinal control of the sympathetic nervous system below the lesion level frequently results in orthostatic hypotension [33-34]. Orthostatic hypotension is defined by the Consensus Committee of the American Autonomic Society and the American Academy of Neurology as a decrease in systolic blood pressure of $\geq 20 \mathrm{mmHg}$ or a decrease in diastolic blood pressure of $\geq 10 \mathrm{mmHg}$ when the subject moves from an upright to supine posture, regardless of whether symptoms occur [35]. The two grades of severity are asymptomatic and symptomatic. Symptoms may include dizziness, nausea, light-headedness, or faintness [36]. Physical signs include pallor, diaphoresis, or loss of 
consciousness. Orthostatic hypotension is a common problem after acute cervical and high thoracic SCI. Illman et al. found that patients with acute SCI experienced a drop in blood pressure with mobilization 73.6 percent of the time and that 58.9 percent of episodes were symptomatic [20]. With time, the frequency and severity of orthostatic hypotension diminish.

Several mechanisms contribute to orthostatic hypotension in individuals with SCI. Interruption of efferent pathways from the brain stem vasomotor center to the sympathetic nerves involved in vasoconstriction causes failure of short-term blood pressure regulation [37-38], which leads to pooling of blood in the viscera and dependent vasculature. Resting catecholamine levels are lower in individuals with cervical SCI compared with those with paraplegia and nondisabled individuals, and no significant increase in epinephrine or norepinephrine levels is found when people with tetraplegia undergo a HUT [39-40]. Adaptation to orthostatic hypotension is the result of numerous mechanisms, including recovery of spinal sympathetic reflexes, development of spasticity and increased muscle tone, and changes in the renin-angiotensin system [36]. Cerebral blood flow may be maintained despite a continued drop in systemic blood pressure with upright challenge [41].

\section{AUTONOMIC DYSREFLEXIA}

In addition to orthostatic hypotension, individuals with SCI can also be affected by sudden bouts of hypertension (triggered by afferent stimuli below the lesion level) known as $\mathrm{AD}[8,36]$. This condition is not only characterized by increased arterial blood pressure but can also be accompanied by piloerection, chills or shivering, pounding headache, paresthesias, flushing, and diaphoresis above the lesion level, as well as nasal congestion, anxiety, malaise, and nausea [36]. Previously, researchers believed that orthostatic hypotension was confined to the acute phase of SCI and AD to the chronic phase of SCI. However, the presence of $\mathrm{AD}$ in the early phases of SCI has recently been reported [42-43].

$\mathrm{AD}$ usually occurs as a result of noxious or nonnoxious peripheral or visceral stimulation below the lesion level and primarily affects subjects with lesions above the outflow to the splanchnic and renal vascular beds (T5T6). AD is found in subjects with both complete and incomplete lesions $[13,44]$. The incidence of $\mathrm{AD}$ in indi- viduals with SCI varies from 20 to 70 percent of the atrisk SCI population, regardless of age at injury [45-46]. Both noxious and nonnoxious stimulation below the lesion level can induce a widespread activation of the sympathetic nervous system demonstrated by an increase in norepinephrine release [36,47-48]. Initially, based on recordings of peripheral sympathetic nerve activity, this catecholamine release was interpreted as end-organ supersensitivity [49]. However, careful investigations of regional noradrenalin spillover demonstrated significant increases in norepinephrine only below the lesion level, thus making the theory of end-organ supersensitivity less likely $[47,50]$. This catecholamine release induces vasoconstriction in the majority of vascular beds below the level of injury: muscle, skin, kidneys, and presumably also the splanchnic vascular bed [47,50-51]. The baroreceptors are activated by the resultant increase in arterial blood pressure and act to buffer the vasoconstriction through dilation of vascular beds above the lesion level (with intact central control) and through reduction in HR (vagal innervation to the heart is unaffected by SCI).

This inappropriate activation of the sympathetic nervous system associated with $\mathrm{AD}$ occurs several times a day and may even occur asymptomatically [52-53]. This means that the phenomena of $\mathrm{AD}$ is part of a continuum from no symptoms (asymptomatic $\mathrm{AD}$, see Figure) to full-blown AD. Presently, neither a common classification for characterizing this continuum nor a system for grading this reaction exist that could lead to classification of different severities of AD.

Several factors that could trigger $\mathrm{AD}$ have been described in the literature. Irritation of the urinary bladder and gastrointestinal tract are among the most common causes of this condition [36,54]. Catheterization and manipulation of an indwelling catheter, urinary tract infection, detrusor sphincter dyssynergia, and bladder percussion are all well-known precipitating factors. Stimuli that would be noxious if pain sensation was preserved, such as bone fractures or joint displacements, may also be triggering factors. Sexual activity may induce AD in both sexes, and the risk of $\mathrm{AD}$ during pregnancy and delivery is also increased. Furthermore, researchers report iatrogenic triggering factors, such as cystoscopy, cystometry, vibration or electrostimulation for ejaculation, as well as electrical stimulation of muscles [55-57]. 


\section{TEMPERATURE DYSREGULATION}

Thermodysregulation is a well-recognized clinical phenomena after SCI, first described in 1878 by Pfluger (see Colachis and Otis and Schmidt and Chan [58-59]). It occurs in the acute phase of SCI and can potentially last a lifetime. Although thermoregulation is recognized as an autonomic function, the precise mechanisms of dysregulation have not been fully elucidated. The degree of dysregulation appears related to injury level and perhaps to degree of completeness of SCI, similar to the pattern of AD [60]. However, completeness of SCI has not yet been well correlated and is not precisely correlated with the degree of thermodysregulation in individuals with SCI. Nonetheless, temperature is easy to measure and classify, even in the very early stages postinjury. Therefore, thermodysregulation may be a useful means of early assessment of autonomic function, although further research will be needed.

Thermodysregulation falls into three categories based on the available literature. The first is the well-known poikilothermia, often called an "environmental fever," that also relates to hypothermia from prolonged cold exposure. The second is termed "quad fever" and relates to a fever without an infectious source occurring in the first several weeks to months after SCI. The third, increasingly studied in the exercise literature, is exercise-induced fever.

Body temperature is under direct autonomic control via hypothalamic regulation. Peripheral cold and warm receptors project to the hypothalamus via the spinal cord, although deep temperature sensors are also present [61]. When core temperature decreases, sympathetic (noradrenergic) mechanisms induce piloerection, shivering, and vasoconstriction to produce body heat and shunt blood away from the cool surface. Areas lacking connection between the hypothalamus and the sympathetic system do not mount this response. Given a large enough surface area lacking these mechanisms, core temperature will decline. In practical terms, individuals with lesions at T6 and above exhibit the problem, since a loss of descending sympathetic control of more than half of the body is present. Although individuals with lower injury levels exhibit no response to cold in the legs, this does not result in a clinically significant alteration in core temperature. Individuals with tetraplegia usually exhibit a more marked manifestation than individuals with paraplegia, both from the standpoint of lack of hypothalamic connection to the spinal sympathetic circuits and from the standpoint of reduced surface area that can respond.

Quad fever was described by Sugarman et al. in 1982 [62]. Although clinically recognized, it is not widely discussed in the literature and deserves considerable investigation into the possible controlling mechanism. Quad fever occurs in individuals with tetraplegia and occasionally those with high paraplegia. Patients present with fever, often exceeding $40^{\circ} \mathrm{C}\left(101.5^{\circ} \mathrm{F}\right)$, although only a mild elevation in core temperature may be present. This is a diagnosis of exclusion because infection, thromboembolic disease, inflammation, and atelectasis must be ruled out as sources of fever before quad fever can be diagnosed. Blood pressure and pulse alterations are not a component, since they would suggest a noxious source. No existing theories explain this early phenomena, and since patients are in the hospital in an environmentally controlled setting, poikilothermia also does not explain it. Alterations in the hypothalamic axis can be suspected, particularly in light of changes in hypothalamic afferents, but have not been explored. As with poikilothermia, the role of completeness has not been correlated. The inability of patients to get rid of excess heat by sweating may play a role.

Exercise-induced hyperthermia has been more widely studied in recent years. This fever is again more common in persons with tetraplegia, since they display greater difficulty in dispersing endogenously produced heat [63]. Persons with tetraplegia have a greater increase in body temperature with exercise than persons with paraplegia, even at equal peak oxygen consumption. A prolonged period of increased body temperature is also noted in tetraplegia, with delay in normalization of core temperature. However, neither persons with paraplegia nor those with tetraplegia show any alteration in thigh skin temperature, which confirms the absence of temperature regulation in all levels of complete SCI. Again, degree of completeness of SCI has not been adequately studied. High core temperature can be combated by cool- water foot baths before and during exercise [64]. As has been observed in other forms of temperature dysregulation, environmental techniques are successful in restoring normal body temperature. Mechanisms of temperature dysregulation need further study, particularly with regard to incomplete lesions. Differentiating between those with and without temperature dysregulation may be helpful in discerning those with autonomic incompleteness, even in the presence of motor and sensory completeness. 
Core temperatures (oral, rectal, or tympanic) should be regularly and accurately assessed, along with ambient temperature, amount of activity, and recent exposure to an alternate environment. In the acute phase of SCI, temperature may be the easiest parameter to test and measure for autonomic function. Both core body temperature and skin temperature above and below the level of injury are helpful in assessing temperature and autonomic function.

\section{SWEATING DISTURBANCES}

Hyperhidrosis denotes increased eccrine sweating [65]. Excessive sweating is a common complaint among individuals with SCI. A significant number of individuals with SCI experience episodic hyperhidrosis associated with AD, orthostatic hypotension, or posttraumatic syringomyelia [66-69]. Although the most common pattern in SCI is profuse sweating above the lesion level with minimal or no sweating (hypohidrosis, anhidrosis) below the lesion level, sweating exclusively below the lesion level can also be observed. These probably represent different autonomic mechanisms, the pathways of which have not been elucidated.

\section{DISCUSSION AND CONCLUSIONS}

SCI, especially with cervical lesion levels, may be life-threatening because of the imbalance in the autonomic nervous system. Furthermore, this imbalance might be a risk factor for further deterioration of neurological function following SCI. This is a preliminary report of the discussion of the joint committee of the ASIA and ISCoS concerning the development of assessment criteria for general autonomic function testing following SCI. Presently the committee recommends the recognition and assessment of the following conditions: neurogenic shock, cardiac dysrhythmias, orthostatic hypotension, $\mathrm{AD}$, temperature dysregulation, and hyperhidrosis. Members of the committee propose that in the future, in addition to already established motor and sensory assessment standards, the assessment of autonomic functions be a part of clinical evaluation of individuals with SCI.

\section{ACKNOWLEDGMENTS}

Portions of this article were presented as "Evaluation of autonomic dysfunction following spinal cord injury. Report of the ASIA General Autonomic Function Committee" at the preconference course, "Outcome measures for spinal cord injury” of the 31st Annual Meeting of the ASIA, May 12-14, 2005, in Dallas, Texas.

This material was unfunded at the time of manuscript publication.

The authors have declared that no competing interests exist.

\section{REFERENCES}

1. Blood pressure management after acute spinal cord injury. Neurosurgery. 2002;50(3 Suppl):S58-62. [PMID: 12431288]

2. Hadley MN, Walters BC, Grabb PA, Oyesiku NM, Przybylski GJ, Resnick DK, Ryken TC, Mielke DH. Guidelines for the management of acute cervical spine and spinal cord injuries. Clin Neurosurg. 2002;49:407-98. [PMID: 12506565]

3. Marino RJ, Barros T, Biering-Sorensen F, Burns SP, Donovan WH, Graves DE, Haak M, Hudson LM, Priebe MM; ASIA Neurological Standards Committee 2002. International standards for neurological classification of spinal cord injury. J Spinal Cord Med. 2003;(26 Suppl 1):S50-56. [PMID: 16296564]

4. Krassioukov AV, Claydon VE. The clinical problems in cardiovascular control following spinal cord injury: An overview. Prog Brain Res. 2006;152:223-29. [PMID: 16198703]

5. Mathias CJ, Christensen NJ, Frankel HL, Spalding JM. Cardiovascular control in recently injured tetraplegics in spinal shock. Q J Med. 1979;48(190):273-87. [PMID: 504551]

6. Bilello JF, Davis JW, Cunningham MA, Groom TF, Lemaster D, Sue LP. Cervical spinal cord injury and the need for cardiovascular intervention. Arch Surg. 2003;138(10):1127-29. [PMID: 14557131]

7. Vale FL, Burns J, Jackson AB, Hadley MN. Combined medical and surgical treatment after acute spinal cord injury: Results of a prospective pilot study to assess the merits of aggressive medical resuscitation and blood pressure management. J Neurosurg. 1997;87(2):239-46. [PMID: 9254087]

8. Mathias CJ, Frankel HL. Autonomic disturbances in spinal cord lesions. In: Mathias CJ, Bannister R, editors. Autonomic failure: A textbook of clinical disorders of the autonomic nervous system. New York (NY): Oxford University Press; 2002. p. 494-513. 
9. Glenn MB, Bergman SB. Cardiovascular changes following spinal cord injury. Top Spinal Cord Inj Rehabil. 1997; 2(4):47-53.

10. Piepmeier JM, Lehmann KB, Lane JG. Cardiovascular instability following acute cervical spinal cord trauma. Cent Nerv Syst Trauma. 1985;2(3):153-60. [PMID: 3835007]

11. Lehmann KG, Lane JG, Piepmeier JM, Batsford WP. Cardiovascular abnormalities accompanying acute spinal cord injury in humans: Incidence, time course and severity. J Am Coll Cardiol. 1987;10(1):46-52. [PMID: 3597994]

12. Winslow EB, Lesch M, Talano JV, Meyer PR Jr. Spinal cord injuries associated with cardiopulmonary complications. Spine. 1986;11(8):809-12. [PMID: 3810297]

13. Furlan JC, Fehlings MG, Shannon P, Norenberg MD, Krassioukov AV. Descending vasomotor pathways in humans: Correlation between axonal preservation and cardiovascular dysfunction after spinal cord injury. J Neurotrauma. 2003;20(12):1351-63. [PMID: 14748983]

14. Nacimiento W, Noth J. What, if anything, is spinal shock? Arch Neurol. 1999;56(8):1033-35. [PMID: 10448814$]$

15. Atkinson PP, Atkinson JL. Spinal shock. Mayo Clin Proc. 1996;71(4):384-89. [PMID: 8637263]

16. Ditunno JF, Little JW, Tessler A, Burns AS. Spinal shock revisited: A four-phase model. Spinal Cord. 2004;42(7): 383-95. [PMID: 15037862]

17. Grimm DR, DeMeersman RE, Garofano RP, Spungen AM, Bauman WA. Effect of provocative maneuvers on heart rate variability in subjects with quadriplegia. Am J Physiol. 1995;268(6 Pt 2):H2239-45. [PMID: 7611473]

18. Inoue K, Miyake S, Kumashiro M, Ogata H, Yoshimura O. Power spectral analysis of heart rate variability in traumatic quadriplegic humans. Am J Physiol. 1990;258(6 Pt 2): H1722-26. [PMID: 2360666]

19. Wecht JM, De Meersman RE, Weir JP, Bauman WA, Grimm DR. Effects of autonomic disruption and inactivity on venous vascular function. Am J Physiol Heart Circ Physiol. 2000;278(2):H515-20. [PMID: 10666083]

20. Illman A, Stiller K, Williams M. The prevalence of orthostatic hypotension during physiotherapy treatment in patients with an acute spinal cord injury. Spinal Cord. 2000;38(12): 741-47. [PMID: 11175374]

21. Pine ZM, Miller SD, Alonso JA. Atrial fibrillation associated with autonomic dysreflexia. Am J Phys Med Rehabil. 1991;70(5):271-73. [PMID: 1910653]

22. Mathias CJ. Bradycardia and cardiac arrest during tracheal suction-Mechanisms in tetraplegic patients. Eur J Intensive Care Med. 1976;2(4):147-56. [PMID: 793846$]$

23. Frankel HL, Mathias CJ, Spalding JM. Mechanisms of reflex cardiac arrest in tetraplegic patients. Lancet. 1975; 2(7946):1183-85. [PMID: 53662]
24. Silbert PL, Davis JM. Late asystole in high cervical spinal cord injury: Case report. Paraplegia. 1990;28(2):137-40. [PMID: 2235023]

25. Dixit S. Bradycardia associated with high cervical spinal cord injury. Surg Neurol. 1995;43(5):514. [PMID: 7660293]

26. Prakash M, Raxwal V, Froelicher VF, Kalisetti D, Vieira A, O’Mara G, Marcus R, Myers J, Kiratli J, Perkash I. Electrocardiographic findings in patients with chronic spinal cord injury. Am J Phys Med Rehabil. 2002;81(8):601-8. [PMID: 12172070]

27. Forrest GP. Atrial fibrillation associated with autonomic dysreflexia in patients with tetraplegia. Arch Phys Med Rehabil. 1991;72(8):592-94. [PMID: 2059140]

28. Pagani M, Lombardi F, Guzzetti S, Rimoldi O, Furlan R, Pizzinelli P, Sandrone G, Malfatto G, Dell'Orto S, Piccaluga E. Power spectral analysis of heart rate and arterial pressure variabilities as a marker of sympatho-vagal interaction in man and conscious dog. Circ Res. 1986;59(2):178-93. [PMID: 2874900]

29. Pomeranz B, Macaulay RJ, Caudill MA, Kutz I, Adam D, Gordon D, Kilborn KM, Barger AC, Shannon DC, Cohen RJ, et al. Assessment of autonomic function in humans by heart rate spectral analysis. Am J Physiol. 1985;248(1 Pt 2): H151-53. [PMID: 3970172]

30. Ahmed MW, Kadish AH, Parker MA, Goldberger JJ. Effect of physiologic and pharmacologic adrenergic stimulation on heart rate variability. J Am Coll Cardiol. 1994; 24(4):1082-90. [PMID: 7930202]

31. Bunten DC, Warner AL, Brunnemann SR, Segal JL. Heart rate variability is altered following spinal cord injury. Clin Auton Res. 1998;8(6):329-34. [PMID: 9869550]

32. Wecht JM, Radulovic M, Weir JP, Lessey J, Spungen AM, Bauman WA. Partial angiotensin-converting enzyme inhibition during acute orthostatic stress in persons with tetraplegia. J Spinal Cord Med. 2005;28(2):103-8. [PMID: 15889697]

33. Mathias CJ. Orthostatic hypotension and paroxysmal hypertension in humans with high spinal cord injury. Prog Brain Res. 2006;152:231-43. [PMID: 16198704]

34. Claydon VE, Steeves JD, Krassioukov AV. Orthostatic hypotension following spinal cord injury: Understanding clinical pathophysiology. Spinal Cord. 2006;44(6):341-51. [PMID: 16304564]

35. Consensus statement on the definition of orthostatic hypotension, pure autonomic failure, and multiple system atrophy. The Consensus Committee of the American Autonomic Society and the American Academy of Neurology. Neurology. 1996;46(5):1470. [PMID: 8628505]

36. Teasell R, Arnold AP, Krassioukov AV, Delaney GA. Cardiovascular consequences of loss of supraspinal control of the sympathetic nervous system after spinal cord injury. Arch Phys Med Rehabil. 2000;81(4):506-16. [PMID: 10768544] 
37. Blackmer J. Rehabilitation medicine: 1. Autonomic dysreflexia. CMAJ. 2003;169(9):931-35. [PMID: 14581313]

38. Claydon VE, Hol AT, Eng JJ, Krassioukov AV. Cardiovascular responses and postexercise hypotension after arm cycling exercise in subjects with spinal cord injury. Arch Phys Med Rehabil. 2006;87(8):1106-14. [PMID: 16876557]

39. Mathias CJ, Christensen NJ, Frankel HL, Peart WS. Renin release during head-up tilt occurs independently of sympathetic nervous activity in tetraplegic man. Clin Sci. 1980; 59(4):251-56. [PMID: 7000419$]$

40. Claydon VE, Krassioukov AV. Orthostatic hypotention and autonomic pathways after spinal cord injury. J Neurotrauma. 2006;23(12):1713-25. [PMID: 17184183]

41. Gonzalez F, Chang JY, Banovac K, Messina D, MartinezArizala A, Kelley RE. Autoregulation of cerebral blood flow in patients with orthostatic hypotension after spinal cord injury. Paraplegia. 1991;29(1):1-7. [PMID: 2023766]

42. Krassioukov AV, Furlan JC, Fehlings MG. Autonomic dysreflexia in acute spinal cord injury: An under-recognized clinical entity. J Neurotrauma. 2003;20(8):707-16. [PMID: 12965050]

43. Silver JR. Early autonomic dysreflexia. Spinal Cord. 2000; 38(4):229-33. [PMID: 10822393]

44. Helkowski WM, Ditunno JF Jr, Boninger M. Autonomic dysreflexia: Incidence in persons with neurologically complete and incomplete tetraplegia. J Spinal Cord Med. 2003; 26(3):244-47. [PMID: 14997966]

45. Braddom RL, Rocco JF. Autonomic dysreflexia. A survey of current treatment. Am J Phys Med Rehabil. 1991;70(5): 234-41. [PMID: 1910647]

46. Lindan R, Joiner E, Freehafer AA, Hazel C. Incidence and clinical features of autonomic dysreflexia in patients with spinal cord injury. Paraplegia. 1980;18(5):285-92. [PMID: 7443280]

47. Karlsson AK, Friberg P, Lonnroth P, Sullivan L, Elam M. Regional sympathetic function in high spinal cord injury during mental stress and autonomic dysreflexia. Brain. 1998;121(Pt 9):1711-19. [PMID: 9762959]

48. Karlsson AK, Elam M, Friberg P, Biering-Sorensen F, Sullivan L, Lonnroth P. Regulation of lipolysis by the sympathetic nervous system: A microdialysis study in normal and spinal cord-injured subjects. Metabolism. 1997;46(4): 388-94. [PMID: 9109841]

49. Stjernberg L, Blumberg H, Wallin BG. Sympathetic activity in man after spinal cord injury. Outflow to muscle below the lesion. Brain. 1986;109(Pt 4):695-715. [PMID: 3730811]

50. Gao SA, Ambring A, Lambert G, Karlsson AK. Autonomic control of the heart and renal vascular bed during autonomic dysreflexia in high spinal cord injury. Clin Auton Res. 2002;12(6):457-64. [PMID: 12598950]
51. Corbett JL, Debarge O, Frankel HL, Mathias C. Cardiovascular responses in tetraplegic man to muscle spasm, bladder percussion and head-up tilt. Clin Exp Pharmacol Physiol. 1975;Suppl 2:189-93. [PMID: 241523]

52. Kirshblum SC, House JG, O’Connor KC. Silent autonomic dysreflexia during a routine bowel program in persons with traumatic spinal cord injury: A preliminary study. Arch Phys Med Rehabil. 2002;83(12):1774-76. [PMID: 12474185]

53. Linsenmeyer TA, Campagnolo DI, Chou IH. Silent autonomic dysreflexia during voiding in men with spinal cord injuries. J Urol. 1996;155(2):519-22. [PMID: 8558650]

54. Karlsson AK. Autonomic dysreflexia. Spinal Cord. 1999; 37(6):383-91. [PMID: 10432257]

55. Chang CP, Chen MT, Chang LS. Autonomic hyperreflexia in spinal cord injury patient during percutaneous nephrolithotomy for renal stone: A case report. J Urol. 1991; 146(6):1601-2. [PMID: 1942351]

56. Giannantoni A, Di Stasi SM, Scivoletto G, Mollo A, Silecchia A, Fuoco U, Vespasiani G. Autonomic dysreflexia during urodynamics. Spinal Cord. 1998;36(11):756-60. [PMID: 9848482]

57. Sheel AW, Krassioukov AV, Inglis JT, Elliott SL. Autonomic dysreflexia during sperm retrieval in spinal cord injury: Influence of lesion level and sildenafil citrate. J Appl Physiol. 2005;99(1):53-58. [PMID: 15790691]

58. Colachis SC 3rd, Otis SM. Occurrence of fever associated with thermoregulatory dysfunction after acute traumatic spinal cord injury. Am J Phys Med Rehabil. 1995;74(2): 114-19. [PMID: 7710724]

59. Schmidt KD, Chan CW. Thermoregulation and fever in normal persons and in those with spinal cord injuries. Mayo Clin Proc. 1992;67(5):469-75. [PMID: 1405774]

60. Guttman L. Spinal cord injuries: Comprehensive management and research. 2nd ed. Philadelphia (PA): Blackwell Science Ltd; 1976.

61. Downey JA, Huckaba CE, Myers SJ, Darling RC. Thermoregulation in the spinal man. J Appl Physiol. 1973; 34(6):790-94. [PMID: 4514403]

62. Sugarman B, Brown D, Musher D. Fever and infection in spinal cord injury patients. JAMA. 1982;248(1):66-70. [PMID: 7087094]

63. Price MJ, Campbell IG. Effects of spinal cord lesion level upon thermoregulation during exercise in the heat. Med Sci Sports Exerc. 2003;35(7):1100-1107. [PMID: 12840629]

64. Hagobian TA, Jacobs KA, Kiratli BJ, Friedlander AL. Foot cooling reduces exercise-induced hyperthermia in men with spinal cord injury. Med Sci Sports Exerc. 2004;36(3): 411-17. [PMID: 15076782]

65. Leung AK, Chan PY, Choi MC. Hyperhidrosis. Int J Dermatol. 1999;38(8):561-67. [PMID: 10487442] 
66. Khurana RK. Orthostatic hypotension-induced autonomic dysreflexia. Neurology. 1987;37(7):1221-24. [PMID: 3601087]

67. Jane MJ, Freehafer AA, Hazel C, Lindan R, Joiner E. Autonomic dysreflexia. A cause of morbidity and mortality in orthopedic patients with spinal cord injury. Clin Orth Relat Res. 1982;(169):151-54. [PMID: 7105571$]$
68. Head H, Riddoch G. The automatic bladder, excessive sweating and some other reflex conditions in gross injuries of the spinal cord. Brain. 1917;40:188-263.

69. Kramer KM, Levine AM. Posttraumatic syringomyelia: A review of 21 cases. Clin Orthop Relat Res. 1997;(334): 190-99. [PMID: 9005913]

Submitted for publication October 13, 2005. Accepted in revised form February 3, 2006. 